\title{
Daily and seasonal trends of electricity and water use on pasture-based automatic milking dairy farms
}

\author{
J. Shortall, ${ }^{*}{ }^{1}$ B. O’Brien, ${ }^{*}$ R. D. Sleator, $†$ and J. Upton* \\ ${ }^{*}$ Teagasc, Animal \& Grassland Research and Innovation Centre, Moorepark, Fermoy, Co. Cork, Ireland \\ †Department of Biological Sciences, Cork Institute of Technology, Bishopstown, Co. Cork, Ireland
}

\begin{abstract}
The objective of this study was to identify the major electricity and water-consuming components of a pasture-based automatic milking (AM) system and to establish the daily and seasonal consumption trends. Electricity and water meters were installed on 7 seasonal calving pasture-based AM farms across Ireland. Electricity-consuming processes and equipment that were metered for consumption included milk cooling components, air compressors, AM unit(s), auxiliary water heaters, water pumps, lights, sockets, automatic manure scrapers, and so on. On-farm direct waterconsuming processes and equipment were metered and included AM unit(s), auxiliary water heaters, tubular coolers, wash-down water pumps, livestock drinking water supply, and miscellaneous water taps. Data were collected and analyzed for the 12-mo period of 2015. The average AM farm examined had 114 cows, milking with 1.85 robots, performing a total of 105 milkings/AM unit per day. Total electricity consumption and costs were $62.6 \mathrm{Wh} / \mathrm{L}$ of milk produced and 0.91 cents/L, respectively. Milking (vacuum and milk pumping, within-AM unit water heating) had the largest electrical consumption at $33 \%$, followed by air compressing (26\%), milk cooling (18\%), auxiliary water heating $(8 \%)$, water pumping $(4 \%)$, and other electricity-consuming processes $(11 \%)$. Electricity costs followed a similar trend to that of consumption, with the milking process and water pumping accounting for the highest and lowest cost, respectively. The pattern of daily electricity consumption was similar across the lactation periods, with peak consumption occurring at 0100, 0800, and between 1300 and $1600 \mathrm{~h}$. The trends in seasonal electricity consumption followed the seasonal milk production curve. Total water consumption was $3.7 \mathrm{~L}$ of water/L of milk produced. Water consumption associated with the dairy herd at the milking shed
\end{abstract}

Received June 28, 2017.

Accepted September 24, 2017.

${ }^{1}$ Corresponding author: john.shortall@teagasc.ie represented $42 \%$ of total water consumed on the farm. Daily water consumption trends indicated consumption to be lowest in the early morning period $(0300-0600 \mathrm{~h})$, followed by spikes in consumption between 1100 and $1400 \mathrm{~h}$. Seasonal water trends followed the seasonal milk production curve, except for the month of May, when water consumption was reduced due to aboveaverage rainfall. This study provides a useful insight into the consumption of electricity and water on a pasture-based AM farms, while also facilitating the development of future strategies and technologies likely to increase the sustainability of AM systems.

Key words: automatic milking system, pasture-based system, electricity consumption, water consumption, sustainability

\section{INTRODUCTION}

The abolition of the European Union (EU) milk quota regimen has presented EU dairy farmers with the opportunity to increase milk production for the first time in over 3 decades. Irish milk production was predicted to have the potential to increase by $50 \%$ on pre-quota abolition levels (DAFM, 2010), with the value of that product also predicted to increase (DAFM, 2015). This increase in production is due primarily to the current underutilization of existing animals and lands (O'Donnell et al., 2008). Additional milk production may result in a milk price reduction (Lips and Rieder, 2005) and increased milk price volatility (Dillon et al., 2016). By the end of 2016 , milk production had increased by $35 \%$ over the Food Harvest 2020 baseline milk production levels (CSO, 2017); placing a substantial strain on existing dairy farm labor resources. This, in combination with the shortage of available skilled labor (Teagasc, 2017), has resulted in farmers adopting new technologies to reduce labor demand. One such technology, automatic milking (AM) systems, are being adopted to automate the milking process. This adoption is facilitated by innovative pasture-management methods (Lyons et al., 2013), which enable pasture-based farmers to maintain a large portion of grazed grass in the cow diet. Auto- 
matic milking systems have been found to reduce labor (Mathijs, 2004; Bijl et al., 2007; Shortall et al., 2016) and give greater time flexibility to the farm manager.

However, a significant limitation associated with the adoption of AM is the reduced profitability of the technology relative to conventional milking $(\mathbf{C M})$ technologies of low to medium specification (Rotz et al., 2003; Jago et al., 2006; Shortall et al., 2016). Although the large capital cost associated with AM technology is one of the main factors contributing this, the increased consumption of electricity associated with AM may also be considered a contributing factor (Bijl et al., 2007; Upton and O'Brien, 2013). Whereas the consumption of electricity by both AM (Upton and O'Brien, 2013; Calcante et al., 2016) and CM systems (Upton et al., 2013) have been previously determined, the daily and seasonal trends of electricity consumption in a pasturebased AM systems remain undocumented. Furthermore, electricity consumption can be influenced by on-farm equipment, and the possibility exists to reduce electricity costs through the adoption of energy efficient and renewable technologies. However, the financial prudence of these technologies will be dependent not alone on the capital costs of these technologies, but also on the daily trends of electricity consumption (Upton et al., 2015a).

Water is commonly used to precool milk on AM farms via a tubular cooler; hence, water consumption on AM farms may be significant. It is important to measure water consumption to gain a holistic picture of the energy water nexus on AM farms, as this is essential for comparing equipment efficiencies across farms. Furthermore, on-farm water consumption is necessary background information for the computation of a farm's water-footprint. These data were presented by Murphy et al. (2017) for Irish CM dairy farms; however, information relating to on-farm water usage on AM pasturebased systems remains scant. Although Higham et al. (2017) outlined the trends in water consumption on New Zealand pasture-based CM farms, water consumption in an AM systems has only been reported in relation to the milking area by Artmann and Bohlsen (2000), thus leaving the whole farm and the daily and seasonal trends undocumented. Water use also has a direct effect on electricity costs, as there is an associated cost of pumping water. Thus, the objective of our study was to establish the daily and seasonal trends of electricity and water consumption on AM dairy farms in pasture-based systems over a year-long period.

\section{MATERIALS AND METHODS}

This study was conducted on 7 pasture-based AM farms with a spring-calving system across Ireland.
These farms were selected from a database of clients associated with the extension and advisory section of the Teagasc research, training, and advisory body in Ireland. To be considered for selection, farms had to be pasture-based, spring-calving, milking with an AM system for at least $1 \mathrm{yr}$, and willing to have electricity and water meters installed within their existing infrastructure.

\section{Data Collection}

Data were collected for the 12-mo period from January 1 to December 31, 2015. Electricity and water consumption was recorded using a wireless monitoring system supplied by Carlo Gavazzi (Carlo Gavazzi Automation SpA, Lainate, Italy). Wireless, wide area network routers were used to transport the data from farm to research center, where Powersoft logging and recording software (Carlo Gavazzi Automation SpA) calculated cumulative energy used $(\mathrm{kWh})$ at 15-min intervals for each on-farm electricity- and water-consuming process. Dairy farm processes and equipment that were metered for electrical consumption included milk cooling components, air compressors, AM unit(s), auxiliary water heaters, water pumps, and others, such as lights, sockets, automatic manure scrapers, and so on. On-farm direct water-consuming processes that were metered included AM unit(s), auxiliary water heaters, tubular coolers, wash-down water pumps, livestock drinking water supply, and miscellaneous water taps.

The AM systems were arranged in both single and double unit configurations. A single unit configuration consisted of 1 milking crate, 1 robotic arm, and 1 central compartment housing the pumping and cleaning systems. A double unit configuration consisted of 2 milking crates, 2 robotic arms, and 1 central compartment housing the pumping and cleaning systems for both milking crates. For the purpose of the study, the term AM unit is the equivalent of 1 milking crate. Thus, when output and consumption are expressed per AM unit, it refers to the total AM system consumption divided by the number of milking crates (e.g., double configuration is divided by 2). The compartmentalization of the milk pump, vacuum pump and water heater, along with individual hot and cold water supplies within the AM system did not allow for individual metering of these components on 6 of the 7 study farms. Thus, the electrical consumption and cost data presented in our study for milking is the combined consumption and cost of milk pumping, milking vacuum, and water heating within the AM system. Water consumption data for milking is the combined consumption of both hot and cold water for cleaning of the AM plant. 
Milk production data for these farms were obtained from the companies to which the milk was supplied. Cow numbers were obtained from a monthly questionnaire, completed by each farmer, in which the average number of lactating and nonlactating cows were recorded. Level of concentrate offered to the cows, number of milkings per unit per day, and number of cows milked per unit per day were obtained from the milking system software package on 6 of the 7 farms. These data were unavailable on farm 5 , and in that instance concentrate consumption was calculated retrospectively using the farms purchase records. On-farm infrastructure with regard to the dairy shed (milk cooling, water heating, and so on) were assessed on a one-off visit to each farm, at which time a survey of facilities was conducted.

\section{Data Processing}

Electricity and water data from the Powersoft logging and recording software were exported to Microsoft Excel (Microsoft Corp., Redmond, WA) spreadsheets and subsequently used to compute consumption trends for each individual farm. Electricity costs of individual farms were calculated by combining consumption data with a 2-tier pricing structure for electricity costs, based on the time of day at which the electricity consumption occurred [day tariff $=€ 0.18 / \mathrm{kWh}$; night tariff $=$ $€ 0.08 / \mathrm{kWh}$ for all consumption between 0000 and 0859 h (SEAI, 2016)]. Where necessary, domestic water consumption was subtracted from total water consump- tion. Domestic water consumption was calculated using the number of occupants of the domestic property and the estimated usage/occupant per year, as per Irish Water guidelines (Irish Water, 2016).

The capture of the aforementioned cow inventory, milk data, and AM unit performance data allowed electricity and water consumption and costs to be computed per unit of production, per cow, and per milking, while also allowing the establishment of relationships between electricity consumption per milking unit and the number of milkings per unit.

\section{RESULTS}

\section{General Farm Characteristics}

A description of the general characteristics and infrastructure on each of the 7 study farms is presented in Table 1. Six farms milked with the same type and model of AM system. Average herd size was 114 cows, with an average annual milk production and concentrate supplementation of $5,372 \mathrm{~L} /$ cow and $1,083 \mathrm{~kg} /$ cow, respectively. The average number of AM units was 1.85 /farm, with each unit performing an average of 105 milkings/d and milking an average of 49 cows, 2.15 times per day. Average production per AM unit per day across the study farms was 1,011 L. In total, 13 AM units were monitored across the study farms, with 3 single-unit configurations and 5 double-unit configurations (farm 6 had 2 double-unit configurations).

Table 1. Characteristics and infrastructure of the 7 automatic milking (AM) study farms

\begin{tabular}{|c|c|c|c|c|c|c|c|c|}
\hline \multirow[b]{2}{*}{ Item } & \multicolumn{7}{|c|}{ Farm } & \multirow[b]{2}{*}{ Average } \\
\hline & 1 & 2 & 3 & 4 & 5 & 6 & 7 & \\
\hline \multicolumn{9}{|l|}{ Characteristics } \\
\hline Farm area (ha) & 42 & 44 & 60 & 38 & 30 & 93 & 25 & 47 \\
\hline Dairy herd size (cows) & 97 & 99 & 121 & 86 & 81 & 234 & 83 & 114 \\
\hline Milk production/cow per year (L) & 7,124 & 6,068 & 6,216 & 4,768 & 5,164 & 4,130 & 4,106 & 5,372 \\
\hline Concentrates/cow per year $(\mathrm{kg})$ & 1,684 & 1,046 & 1,284 & 1,228 & 1,111 & 543 & 690 & 1,083 \\
\hline Number of AM units & 2 & 2 & 2 & 1 & 1 & 4 & 1 & 1.85 \\
\hline Average number of cows milked/robot per day ${ }^{1}$ & 37 & 37 & 52 & 68 & $\mathrm{n} / \mathrm{a}^{2}$ & 44 & 54 & 49 \\
\hline Milkings/robot per day & 92 & 82 & 128 & 141 & $\mathrm{n} / \mathrm{a}^{2}$ & 75 & 115 & 105 \\
\hline \multicolumn{9}{|l|}{ Infrastructure } \\
\hline Robot type & A & A & A & A & $\mathrm{B}$ & A & A & - \\
\hline Vacuum pump power $(\mathrm{kW})$ & 1.7 & 1.7 & 1.7 & 1.7 & 2.2 & 1.7 & 1.7 & 1.8 \\
\hline Hot wash frequency/day & 2 & 2 & 2 & 3 & 1 & 2 & 1 & 1.9 \\
\hline Auxiliary water heater size (L) & 150 & 150 & 150 & 200 & 150 & 200 & 200 & 171 \\
\hline Air compressor number & 1 & 1 & 1 & 1 & 1 & 2 & 1 & 1.1 \\
\hline Air compressor power $(\mathrm{kW})$ & 3.7 & 3.7 & 3.7 & 3.7 & 2.2 & 3.7 & 3.7 & 3.5 \\
\hline Milk cooling system ${ }^{3}$ & DX & IB & DX & IB & DX & DX & DX & - \\
\hline Milk precooling system & $\mathrm{TC}^{4}$ & $\mathrm{TC}$ & $\mathrm{TC}$ & $\mathrm{TC}$ & $\mathrm{TC}$ & $\mathrm{TC}$ & $\mathrm{TC}$ & - \\
\hline Wash pump power $(\mathrm{kW})$ & 1.1 & 1.5 & 1.5 & 1.5 & 1.7 & 1 & 1.5 & 1.4 \\
\hline
\end{tabular}

${ }^{1}$ Average for each day that each robot was in use and excludes nonlactating cows.

${ }^{2} \mathrm{n} / \mathrm{a}=$ not available.

${ }^{3} \mathrm{DX}=$ direct expansion cooling system; IB = ice bank cooling system.

${ }^{4} \mathrm{TC}=$ tube cooler. 


\section{Electricity Consumption and Costs Analysis}

The electricity consumption and costs for each of the electricity consuming processes and their contribution to the total farm electricity consumption and cost are outlined in Table 2. Total electricity consumption was $62.6 \mathrm{Wh}$ of electricity/L of milk produced (range $=47-84 \mathrm{Wh} / \mathrm{L}$ ) or $336 \mathrm{kWh} /$ cow (range $=246-422$ $\mathrm{kWh} / \mathrm{cow})$. In total, $53 \%$ of all electricity consumed by the study farms occurred during the period of the higher-cost day rate tariff. The average cost of electricity on the study farms was 0.91 cents/L (range $=$ $0.67-1.22$ cents/L) or $€ 49 /$ cow (range $=€ 36-57 /$ cow) over the 12-mo period. Electricity used in the dairy milking shed accounted for $85 \%$ of the total electricity consumed on farm. Within the dairy milking shed, the major processes of electricity consumption were milking (33\%), air compressing (26\%), milk cooling (18\%), auxiliary water heating (8\%); water pumping (4\%), and other (11\%) made up the remaining proportions, with these consumptions occurring both within and external to the milking shed.

Milking. Milking encompasses the processes of milk pumping, vacuum pumping, water heating within the AM system, and miscellaneous electrical devices associated with the AM system. For the average AM farm described in our study, milking was the largest electricity consuming process $(33 \%$ ), at $20.7 \mathrm{Wh} / \mathrm{L}$ (range $=14-26$ $\mathrm{Wh} / \mathrm{L}$ ) and a cost of 0.30 cents $/ \mathrm{L}$ (range $=0.21-0.35$ cents $/ \mathrm{L}$ ). Fifty-nine percent (range $=44-67 \%$ ) of this consumption occurred during the day rate tariff.

Electricity consumption and cost per AM unit for the average unit and for each configuration (single and double units) are outlined in Table 3 . The average AM unit consumed 7,361 $\mathrm{kWh}$ during 2015, with the average single unit consuming approximately $55 \%$ more electricity per unit at 9,186 kWh than the average unit from a double configuration $(5,992 \mathrm{kWh})$. A similar trend existed when the systems were analyzed by day. However, consumption per milking was similar between the single and double unit systems at 0.20 and 0.19 $\mathrm{kWh}$ per milking, respectively. The average electricity cost of operating an AM unit was €991 per year, with the trend in electricity costs between configurations (single and double) and metrics (per milking day and per milking) mirroring that of electricity consumption.

The relationship between the average electricity consumption per AM unit per day and the average number of milkings per day is outlined in Figure 1a. A coefficient of determination of 0.44 existed between daily electricity consumption per AM unit (kWh) and the number of milkings per AM unit per day, with consumption per day increasing as milkings per day increased. The relationship between the number of milkings per AM unit per day and electricity consumption per day, when expressed per unit of milk produced (Wh/L), had a coefficient of determination of 0.46 , with consumption per day deceasing as the number of milkings increased.

Air Compressor. The requirement for compressed air accounted for $26 \%$ of all electricity consumed on the study farms, requiring $16.5 \mathrm{Wh} / \mathrm{L}$ (range $=13-23$ $\mathrm{Wh} / \mathrm{L}$ ) and costing 0.24 cents $/ \mathrm{L}$ (range $=0.19-0.35$ cents $/$ L). Sixty-five percent (range $=63-69 \%$ ) of this consumption occurred during the higher day rate tariff. The relationship between the average electricity consumption per air compressor per day and the average number of milkings per day is outlined in Figure 1b. A coefficient of determination of 0.56 existed between daily electricity consumption per air compressor unit $(\mathrm{kWh})$ and the number of milkings per air compressor per day, with consumption per day increasing as milkings per day increased. The relationship between

Table 2. Breakdown of the consumption and cost of electricity per liter of milk sold and per cow on the seven study farms for a 12-mo period

\begin{tabular}{|c|c|c|c|c|c|c|c|}
\hline \multirow[b]{2}{*}{ Item } & \multicolumn{4}{|c|}{ Consumption } & \multicolumn{3}{|c|}{ Cost } \\
\hline & $\mathrm{Wh} / \mathrm{L}$ & $\mathrm{kWh} / \mathrm{Cow}$ & $\begin{array}{c}\% \text { Total } \\
\text { consumption }\end{array}$ & $\begin{array}{l}\% \text { Day rate } \\
\text { tariff usage }{ }^{1}\end{array}$ & $\mathrm{c} / \mathrm{L}^{2}$ & $€ /$ Cow & $\%$ Total cost \\
\hline Milking $^{3}$ & 20.7 & 111 & 33 & 59 & 0.30 & 16 & 32 \\
\hline Air compressor & 16.5 & 87 & 26 & 65 & 0.24 & 13 & 26 \\
\hline Milk cooling & 11.3 & 60 & 18 & 59 & 0.17 & 9 & 19 \\
\hline Auxiliary water heating & 4.4 & 27 & 8 & 43 & 0.07 & 4 & 8 \\
\hline Water pumping & 2.7 & 13 & 4 & 78 & 0.03 & 2 & 3 \\
\hline Other ${ }^{4}$ & 7 & 37 & 11 & 66 & 0.10 & 5 & 11 \\
\hline Total & 62.6 & 336 & 100 & $53^{5}$ & 0.91 & 49 & 100 \\
\hline
\end{tabular}

${ }^{1}$ Percentage of electricity consumed from 0900 to $2359 \mathrm{~h}$.

${ }^{2} \mathrm{c} / \mathrm{L}=$ cents per liter of milk sold.

${ }^{3}$ Milking $=$ all use by the milking robots including vacuum pump and water heating within robots.

${ }^{4}$ Other $=$ components such as lighting and motorized manure scrapers.

${ }^{5}$ Average percentage day rate tariff usage. 
Table 3. The average electricity consumption and cost and water consumption per individual automatic milking unit for study farms with a single-unit configuration and double-unit configuration and for all study farms

\begin{tabular}{|c|c|c|c|}
\hline \multirow[b]{2}{*}{ Item } & \multicolumn{2}{|c|}{ Electricity } & \multirow{2}{*}{$\frac{\text { Water }}{\text { Consumption }(\mathrm{L})}$} \\
\hline & Consumption (kWh) & Cost $(€)$ & \\
\hline \multicolumn{4}{|l|}{ Average unit } \\
\hline Annual & $7,361(5,247-9,503)$ & $991(767-1,339)$ & $159,399(130,150-217,170)$ \\
\hline Per milking day ${ }^{2}$ & $20.5(15.0-26.0)$ & $2.76(2.10-3.67)$ & $445(357-595)$ \\
\hline Per milking & $0.19(0.12-0.23)$ & $0.027(0.018-0.032)$ & $4.3(3.7-5.6)$ \\
\hline \multicolumn{4}{|l|}{ Single unit } \\
\hline Annual & $9,186(8,650-9,503)$ & $1,179(1,002-1,339)$ & $179,330(150,850-217,170)$ \\
\hline Per milking day ${ }^{2}$ & $25.2(23.7-26.0)$ & $3.23(2.75-3.67)$ & $491(413-595)$ \\
\hline Per milking & $0.20(0.18-0.21)$ & $0.027(0.026-0.028)$ & $3.9(3.6-4.2)$ \\
\hline \multicolumn{4}{|l|}{ Double unit } \\
\hline Annual & $5,992(5,247-6,770)$ & $850(767-995)$ & $144,450(130,150-163,550)$ \\
\hline Per milking day ${ }^{2}$ & $17.0(15.0-19.0)$ & $2.41(2.10-2.62)$ & $409(357-478)$ \\
\hline Per milking & $0.19(0.12-0.23)$ & $0.027(0.018-0.032)$ & $4.5(3.7-5.6)$ \\
\hline
\end{tabular}

${ }^{1}$ Data are presented on an annual basis, per milking day and per milking event (ranges in parentheses).

${ }^{2}$ Consumption and cost for each day the system was milking.

the number of milkings expressed per air compressor per day and electricity consumption per day when expressed per unit of milk production (Wh/L) had a coefficient of determination of 0.23 , with consumption per day tending to decrease as the number of milkings per day increases.

Milk Cooling. Milk cooling was the third largest electrical consuming process, at $18 \%$ of total consumption. This resulted in $11.3 \mathrm{Wh}$ of electricity being consumed for every liter of milk produced (range = 6.4-21.6 Wh/L), with $59 \%$ (range $=34-75 \%$ ) of this being consumed during the day tariff period. Similar to the trend for electrical consumption, milk cooling was the third largest electricity cost at 0.17 cents/L (range $=0.09-0.25$ cents $/ \mathrm{L}$ ). Average milk cooling efficiency (liters of milk cooled by $1 \mathrm{kWh}$ ) on the study farms was $88 \mathrm{~L} / \mathrm{kWh}$ ( range $=46-156 \mathrm{~L} / \mathrm{kWh}$ ).

Auxiliary Water Heating, Water Pumping, Other. These represented the smallest electricity-consuming processes and costs on the study farms at 4.4 $\mathrm{Wh} / \mathrm{L}$ and 0.07 cents/L, 2.7 Wh/L and 0.03 cents/L, and $7 \mathrm{Wh} / \mathrm{L}$ and 0.10 cents/L for auxiliary water heating, water pumping, and other, respectively. Auxiliary water heating included heating of water for cleaning of the milk storage tank; water pumping included both supply and wash pumps; whereas other included lights, sockets, and automatic manure scrapers.

\section{Electricity Consumption Trend Analysis}

Seasonal Trends. The seasonal effect of electricity consumption is outlined in Figure 2. The profile of consumption followed a similar profile to the milk production curve of a seasonal production system. This was due to the fact that $85 \%$ of total farm electricity consumption occurred in the milking shed. Total monthly farm consumption was at its lowest in January, at $1,798 \mathrm{kWh}$, before rising steadily to $3,538 \mathrm{kWh}$ in March. Consumption remained consistent between March and July, peaking slightly in May at 3,579 kWh. From July, consumption reduced gradually before reaching its second lowest point of the year, at 2,493 $\mathrm{kWh}$ in December. When the trend was analyzed in watt-hours per liter, it was the inverse of the milk production curve, with consumption at its lowest in June at $47 \mathrm{Wh} / \mathrm{L}$ and peaking in January, February, and December at 161, 121, and $120 \mathrm{Wh} / \mathrm{L}$, respectively.

Daily Trends. The daily profile of electricity consumption on farm is shown in Figures 3 a, b, and c for March 24 and 25, May 25 and 26, and September 15 and 16, 2015, respectively. These days were chosen as representative days during the early-, peak-, and late-lactation periods to illustrate the nature of the electricity consumption profile. Although the peaks and troughs of consumption were more pronounced in the late-lactation period, the pattern of consumption was similar across the lactation periods, with peaks at 0100 , 0800, and between 1300 and $1600 \mathrm{~h}$.

\section{Water Consumption Analysis}

The water consumption for each of the main water consuming processes is outlined in Table 4. In total, $3.7 \mathrm{~L}$ of on-farm direct water was required to produce $1 \mathrm{~L}$ of milk across the 7 pasture-based AM study farms monitored. This equates to $2,286,999 \mathrm{~L} / \mathrm{yr}$ or $55 \mathrm{~L} / \mathrm{cow}$ per day. Water consumption was split between water required for livestock and miscellaneous and the dairy 
shed at 58 and $42 \%$, respectively. Water consumed by livestock and miscellaneous purposes was $2.2 \mathrm{~L} / \mathrm{L}$ of milk, which equated to $32 \mathrm{~L} /$ cow per day.

Milking Process. The milking process encompassed the use of water for cleaning the AM unit (both cold and hot water), precooling of milk, auxiliary hot water, and washing down of the milking shed. Total direct water consumption for the milking process was $957,693 \mathrm{~L} /$ yr $(2,623 \mathrm{~L} / \mathrm{d})$ or $1.5 \mathrm{~L} / \mathrm{L}$ of milk. Precooling of milk in the tube-cooler had the largest requirement for water, followed by milking (AM units), the wash-down process, and auxiliary water heating. The average AM unit consumed $159,399 \mathrm{~L} / \mathrm{yr}$ or $445 \mathrm{~L} /$ milking day (Table 3). Single-unit configurations consumed $34,880 \mathrm{~L}$ more water per unit over the 12 -mo period $(82 \mathrm{~L} / \mathrm{d})$ than double-unit configurations. However, when analyzed per milking event (i.e., one cow milking), the singleunit configurations consumed $3.9 \mathrm{~L} /$ unit per milking, whereas the double-unit configurations consumed 4.5 L/unit per milking.

Water Recycling. Water that was used in the tube-cooler for precooling milk was recycled to the wash-down process, the AM units and livestock or miscellaneous purposes (Table 5). Of the water made available for recycling, livestock or miscellaneous process availed of the greatest proportion of it (55\%), followed by the wash-down process (29\%) and the AM units $(16 \%)$. However, when analyzing the recycled water as a proportion of the total consumption for each of the 3 components, it made up $100 \%$ of the water used for the
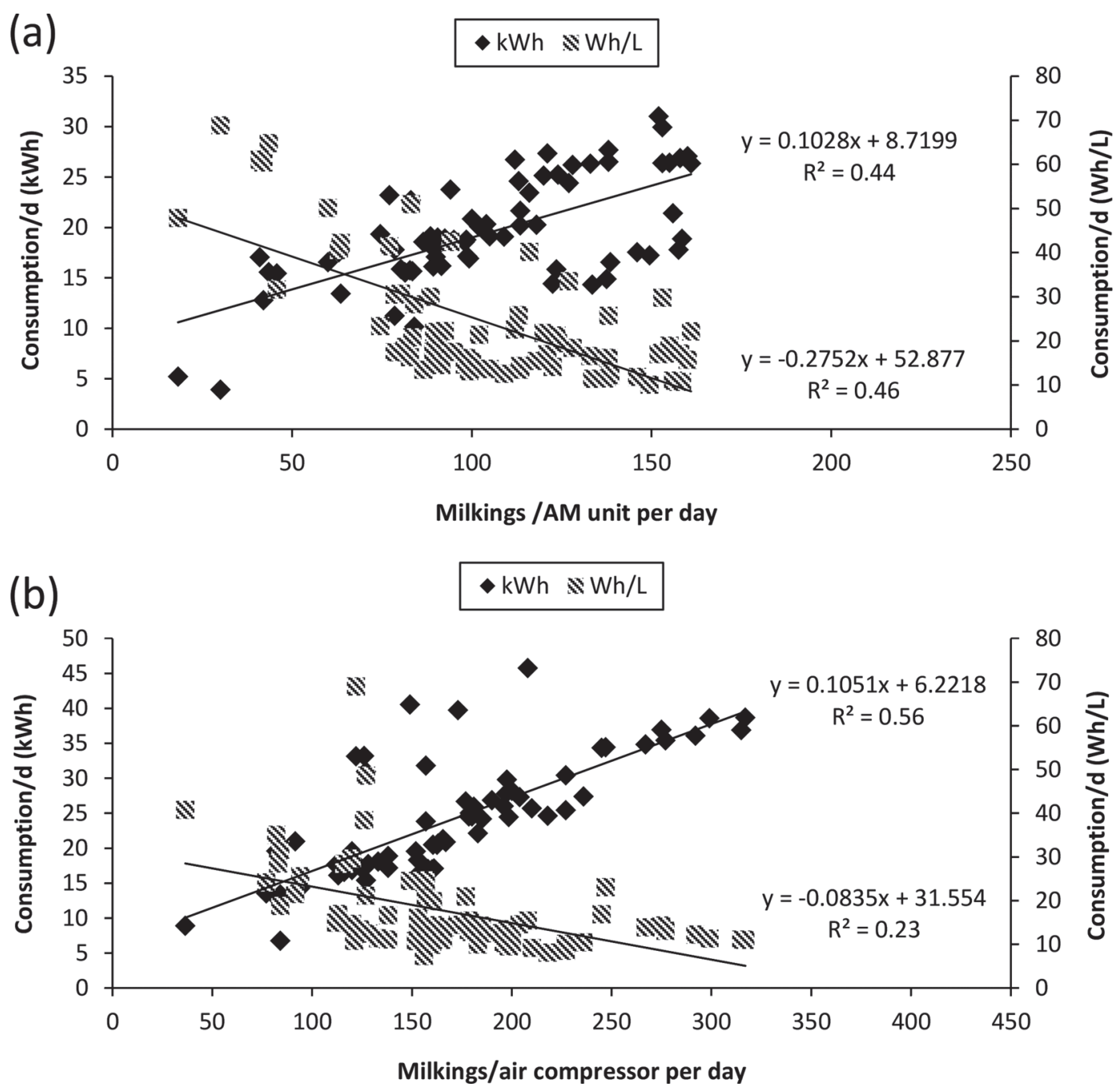

Figure 1. The relationship between (a) the number of milkings per automatic milking (AM) unit per day and daily electricity consumption per AM unit, and (b) the number of milkings per air compressor per day and daily electricity consumption per air compressor. Daily electricity consumption is expressed as kilowatt-hours and watt-hours per liter of milk produced. Each data point represents the average number of milkings per day and the average consumption per day for each of the 12 mo in the study period for 6 of the study farms. 
wash-down process, $37 \%$ of the water for the AM units, and $23 \%$ of the water for livestock or miscellaneous.

\section{Water Consumption Trend Analysis}

Seasonal Trends. The seasonal trend of water consumption is outlined in Figure 4. Similar to the seasonal electricity-consumption profile, water consumption followed a comparable trend to the milk production curve of a seasonal production system. Consumption was at its lowest in January and December, at 105,464 and $126,166 \mathrm{~L}$, respectively. Consumption peaked at 264,051 $\mathrm{L}$ in June; however, contrary to the milk production curve, consumption in May was reduced compared with the preceding and the succeeding 2 mo. When the trend was analyzed on a liter per liter basis, it was again the inverse of the milk production curve, with consumption at its lowest in May at $2.6 \mathrm{~L} / \mathrm{L}$ while peaking in January, February, and December at 6.9, 6.2, and 6.1 L/L, respectively.

Daily Trends. The daily profile of water consumption is illustrated in Figures $5 \mathrm{a}, \mathrm{b}$ and c for March 24 and 25, May 25 and 26, and September 15 and 16, 2015, respectively. These days were chosen as representative days during the early-, peak-, and late-lactation periods to illustrate the nature of the water consumption profile. Water use followed a similar pattern across all 3 lactation time points. Irrespective of season, water use was at its lowest in the early morning period (0300-0600 $\mathrm{h}, 0.8-1.4 \%$ of total daily consumption), with spikes in consumption from 1100 to $1400 \mathrm{~h}(6.5-9.6 \%$ of total daily consumption).

\section{DISCUSSION}

\section{Electricity}

The total farm electricity consumption and costs of the AM farms in our study were greater than those outlined by Upton et al. (2013) on an average Irish CM pasture-based system. This occurred despite the fact that the proportion of electricity used during the higher-cost day rate period (0900-2359 h) was 10\% less in the current study compared with that of Upton et al. (2013); interestingly, Upton et al. (2015b) outlined that the day and night rate tariff was the most suitable electricity pricing structure for dairy farms. Bijl et al. (2007) and Steeneveld et al. (2012) both outlined greater electricity costs for AM systems compared with CM systems on Dutch dairy farms. The main contributors to the consumption of electricity in the current study were milking, air compression, and milk cooling, together accounting for $77 \%$ of total consumption.

The largest of these processes was milking, which included the vacuum pump, milk pump, and water heating within the AM system. Calcante et al. (2016) described how the average AM unit, when configured to perform 3 hot wash cycles per day, used 1.2 $\mathrm{kWh} / 100 \mathrm{~L}$ of milk. This is less than the $2.1 \mathrm{kWh} / 100$ $\mathrm{L}$ of milk reported in the current study. However, the current study was reflective of a full lactation of a seasonal production system, encompassing the shoulder periods of the lactation when small numbers of cows were milking. The farms in our study had an average of 105 milkings/d per AM unit, whereas Calcante et al. (2016) achieved an average of 156 milkings/d per AM

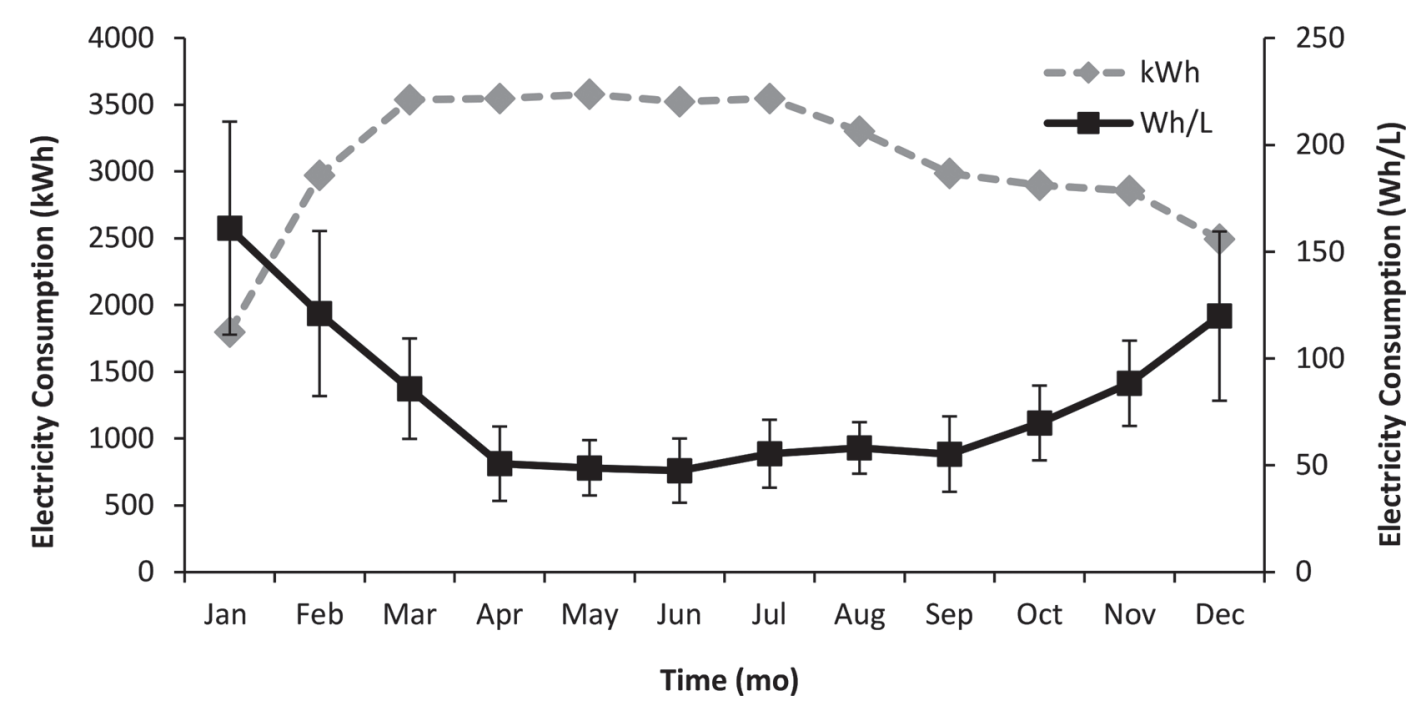

Figure 2. Seasonal trend in total electricity consumption for the average of 7 pasture-based automatic milking study farms over a 12 -mo period, expressed in kilowatt-hours (kWh) and watt-hours per liter of milk produced (Wh/L). Error bars indicate 1 SD. 

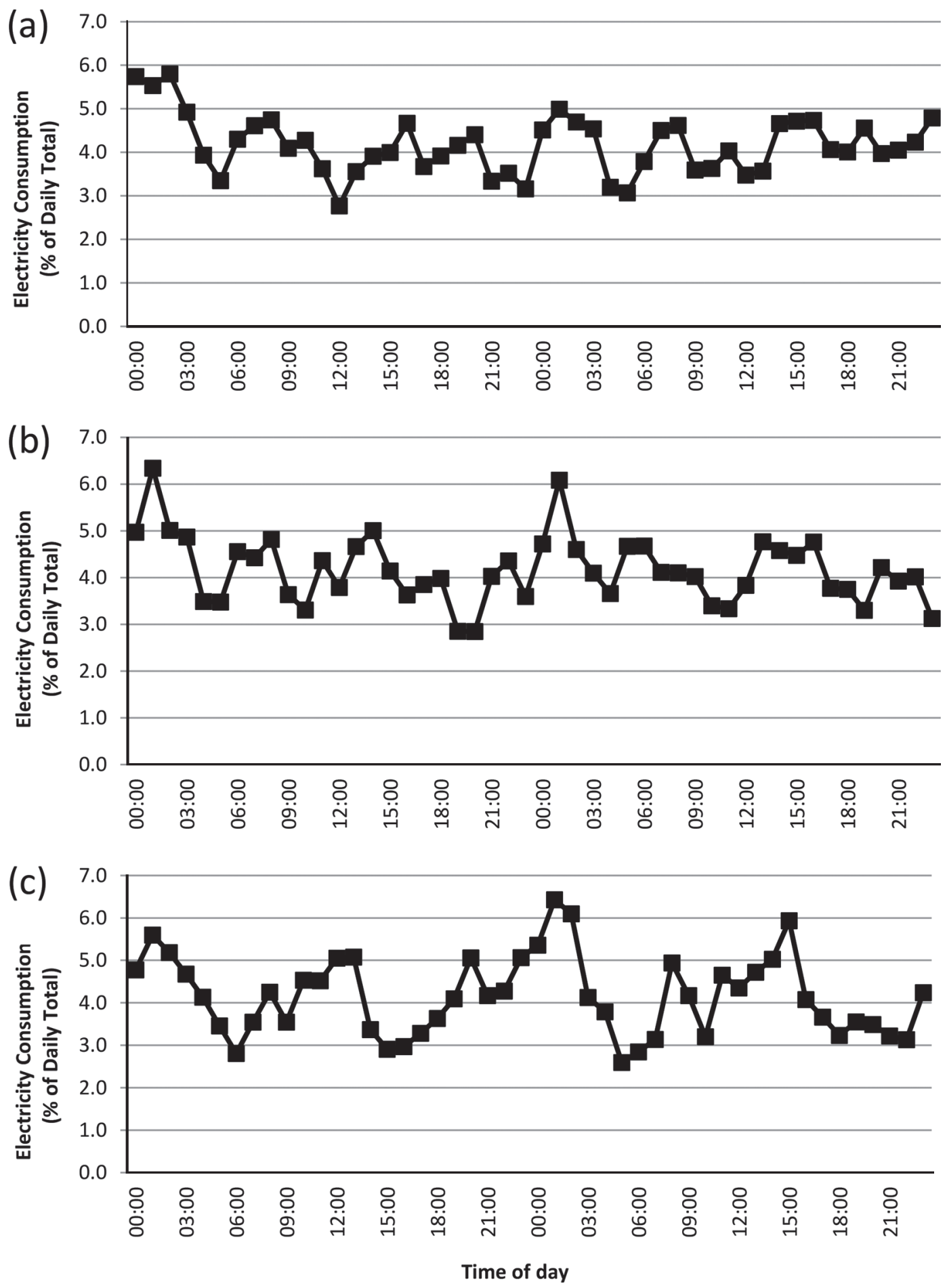

Figure 3. Average percentage of daily total electricity consumption on farm in (a) early lactation (March 24 to 25, 2015), (b) peak lactation (May 25 to 26, 2015), and (c) late lactation (September 15 to 16, 2015) for 7 pasture-based commercial automatic milking farms.

unit. Hence, an inherent base-line electricity demand exists, generated by a fixed number of hot wash cycles per day, irrespective of the number of milkings per day. This is further illustrated in Figure 1a, which revealed that as the number of milkings per AM unit increased, the electricity consumption per liter of milk decreased.

The single-unit configurations monitored in the current study used more electricity (gross $\mathrm{kWh}$ ) per AM 


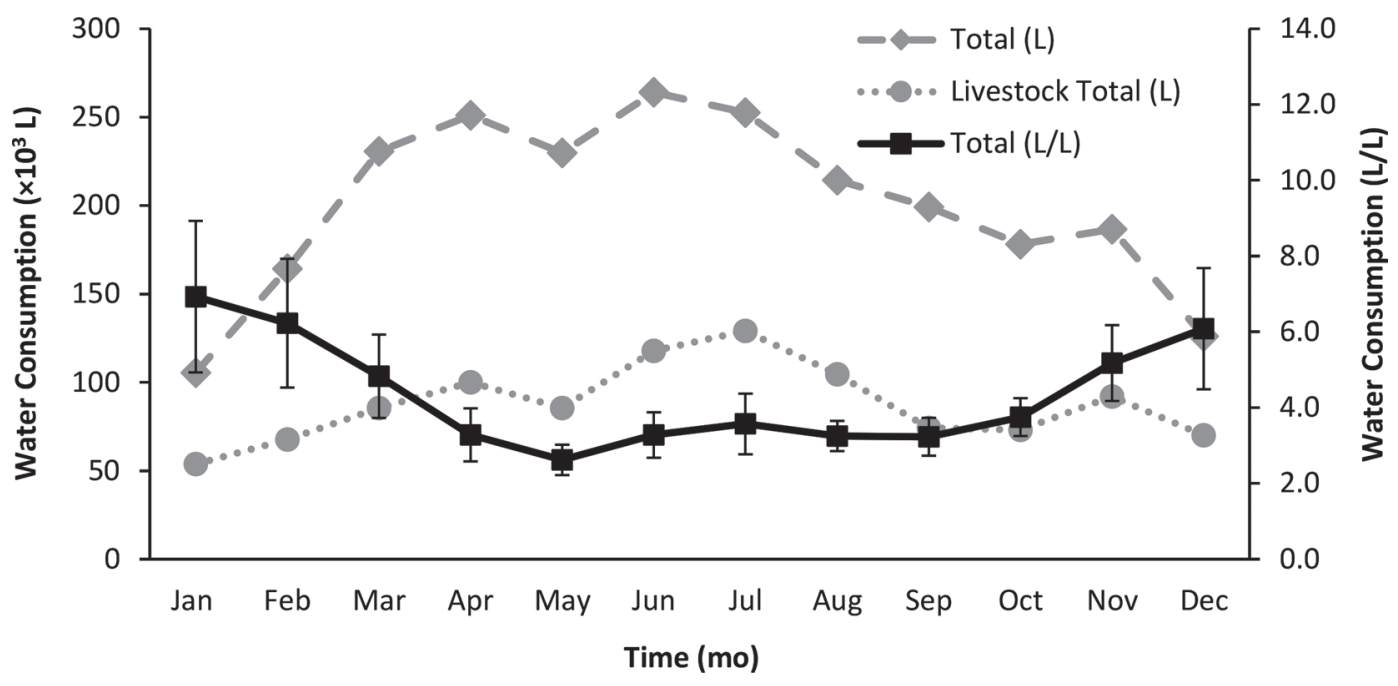

Figure 4. Seasonal trend in total farm direct water consumption for the average of 7 automatic milking study farms over a 12-mo period, expressed in liters and liters of water per liter of milk produced (L/L). Seasonal livestock and miscellaneous water consumption is also outlined in liters. Error bars indicate $1 \mathrm{SD}$.

unit on an annual and daily basis than the double-unit configurations. However, both configurations used a similar quantity of electricity per milking. This would indicate that the differences in electricity consumption per AM unit are as a result of differing stocking densities per AM unit, with single-unit configurations tending to have a higher ratio of cows per unit than double-unit configurations (84 vs. 54 cows/AM unit), resulting in a higher number of milkings per AM unit per day. This may also be observed in Figure 1a, where electricity consumption per day $(\mathrm{kWh})$ increased as milkings per day increased $\left(\mathrm{R}^{2}=0.44\right)$. Thus, $44 \%$ of the variation in electricity consumption per AM unit can be accounted for by the number of milkings performed. Interestingly, 1 of the AM types monitored in our study allowed for the individual metering of the vacuum pump and AM water heater. This showed that water heating for the AM system accounted for $61 \%$ of the unit consumption, with the vacuum pump accounting for $27 \%$ and robot (including milk pump) using $12 \%$. This breakdown facilitates comparisons with the AM system analyzed by Upton and O'Brien (2013), a study that highlighted the frequency of hot washing of the milking equipment as a major difference between an AM and a CM system. This is also contrary to the findings of Artmann and Bohlsen (2000), who found the vacuum pump to be the main electricity user. The average AM farm, in the current study, hot washed the milking unit(s) 1.85 times/d, whereas a typical CM farm may only hot wash on alternate days to coincide

Table 4. Total direct water use on the 7 study farms for a 12 -mo period

\begin{tabular}{lrrrrrr}
\hline Item & \multicolumn{1}{c}{ Liters } & \multicolumn{1}{c}{$\mathrm{SD}$} & $\mathrm{L} / \mathrm{L}^{1}$ & $\mathrm{SD}$ & $\mathrm{L} /$ cow per day & \multicolumn{2}{c}{$\mathrm{SD}$} \\
\hline Total supply $^{2}$ & $2,286,999$ & $650,455.7$ & 3.7 & 0.53 & 55.0 & 4.80 \\
Livestock and miscellaneous $^{3}$ & $1,329,306$ & $351,113.2$ & 2.2 & 0.67 & 32.0 & 13.26 \\
Milking process $^{4}$ & 957,693 & $429,483.9$ & 1.5 & 0.92 & 23.0 & 9.55 \\
Milking,6 $^{5,6}$ & 317,568 & $175,137.7$ & 0.5 & 0.11 & 7.6 & 0.68 \\
Milk precooling $_{\text {Auxiliary water heating }}$ & 729,652 & $404,594.2$ & 1.2 & 0.74 & 17.5 & 10.24 \\
Wash-down $^{6,7}$ & 27,953 & $6,319.3$ & 0.1 & 0.03 & 0.7 & 0.27 \\
\hline
\end{tabular}

${ }^{1} \mathrm{~L} / \mathrm{L}=$ liters of water consumed/liter of milk sold.

${ }^{2} \mathrm{~L} / \mathrm{cow}=$ liters of water/dairy cow per day.

${ }^{3}$ Water consumed by livestock and other miscellaneous use.

${ }^{4}$ Sum of milking process components does not equal milking process total, due to the recycling of water within the milking process network.

${ }^{5}$ Water consumed by the milking robots.

${ }^{6}$ Includes recycled water.

${ }^{7}$ Water consumed through the washing of the milking area. 
Table 5. The proportion of tube-cooler water recycled to differing water consuming process and the proportion of total water for each of those processes obtained from the tube-cooler

\begin{tabular}{lcc}
\hline Item & \% of tube-cooler water & $\begin{array}{c}\text { \% of total component water } \\
\text { obtained from tube-cooler }\end{array}$ \\
\hline Wash-down process & 29 & 100 \\
Livestock and miscellaneous & 55 & 23 \\
Milking (automatic milking units) & 16 & 37 \\
\hline
\end{tabular}

with the washing of the milk storage tank upon milk collection (Upton et al., 2015a).

The requirement for compressed air for the cleaning of milk lines and the opening and closing of entry and exits gates represented a main difference in electricity consumption between AM and CM systems (Upton and O'Brien, 2013). This component alone accounted for $>25 \%$ of the total farm electricity consumption in the current study. A study by Calcante et al. (2016) established that a wrongly sized air compressor can increase electricity consumption by $25 \mathrm{kWh} / \mathrm{d}$, resulting in substantially increased running costs. Similar to the AM unit, we noted a tendency for the consumption of electricity associated with the air compressor to increase as milkings increased. This was expected, given that the air compressor is heavily involved in the guidance of the robotic arm, operating the entry and exits gates on the AM unit, drafting gates, and postselection grazing gates. Milk cooling was the third-largest consumer of electricity on the farms measured, at $11.3 \mathrm{Wh} / \mathrm{L}$. This resulted in a milk cooling efficiency of $88 \mathrm{~L} / \mathrm{kWh}$, which was $11 \mathrm{~L} / \mathrm{kWh}$ more efficient than the CM cooling systems described by Upton et al. (2013) and is likely a consequence of a more gradual and constant supply of milk through the tubular cooler and into the milk storage tank, as an AM unit is operational for milking for almost $24 \mathrm{~h} / \mathrm{d}$.

The seasonal electricity consumption trend followed a similar pattern to the seasonal spring calving milk production curve. This is due to the fact $85 \%$ of total electricity consumption occurred in the milking shed. We noted a greater volume of milk to cool in the midlactation period, as cows were producing peak milk volumes at that time. This period of maximum milk production also necessitates a greater number of milkings per AM unit per day and, as demonstrated earlier, electricity consumption per AM unit increased as the number of milkings increased. However, when the trend was analyzed per liter of milk production, a dilution effect can clearly be seen, with the months of greatest milk production resulting in the lowest consumption per liter.

Daily electricity-consumption profiles follow a substantially different trend to that of the CM system described by Upton et al. (2013), which followed the pattern of twice-daily batch milking. The trend in the current study, irrespective of season, was more consistent, represented by multiple smaller peaks in consumption each day, with maximum consumption per hour at the highest point being $6.5 \%$ of daily total. This results in a more constant demand for electricity, which in turn may make AM systems more suitable than CM systems for operation in association with renewable energy technologies. Electricity consumption was at one of its lowest points in the early morning period. Although milking distribution data were not measured in the current study, this time coincided with a recognized period of reduced visitation and low robot utilization (John et al., 2016). Variation between seasons was limited, with the late-lactation period displaying more pronounced peaks and troughs compared with early lactation. Again, this may be a direct result of a lower utilization rate of the AM unit during the troughs in late lactation.

\section{Water}

Total on-farm direct water consumption was $3.7 \mathrm{~L}$ of water/L of milk sold. This is less than the $11.7 \mathrm{~L} / \mathrm{L}, 6.4$ $\mathrm{L} / \mathrm{L}$, and $5.7 \mathrm{~L} / \mathrm{kg}$ of fat- and protein-corrected milk outlined for CM pasture-based systems by Ridoutt et al. (2010), Murphy et al. (2014), and Murphy et al. (2017), respectively. The average of $55 \mathrm{~L} / \mathrm{cow}$ per day reported in our study was also substantially less than the 113 L/cow per day reported by Higham et al. (2017) for New Zealand nonirrigated CM pasture-based systems; although $26 \%$ of livestock drinking water was reported to be lost to leaks on the New Zealand farms. Water use was split 42 and $58 \%$ between the milking process and livestock or miscellaneous, respectively. Thus, water consumption associated with the milking process was $1.5 \mathrm{~L} / \mathrm{L}$. Precooling of milk represented the largest consumer of water within the milking process and was in agreement with Murphy et al. (2014) in relation to CM systems. However, the consumption was $0.5 \mathrm{~L} / \mathrm{L}$ less in the average AM precooling system of the current study compared with the CM system of Murphy et al. (2014). An average milk cooling ratio of $1.2 \mathrm{~L}$ of water for each liter of milk (range $=0.7-2.1 \mathrm{~L} / \mathrm{L}$ ) was observed at the tubular cooler. Finding efficient recycling strategies for 
this precooling water will be key for reducing the direct water footprint of the dairy farm (Murphy et al., 2014). In the current study, this water was used on-farm by the milking robots and for the wash-down of the milking area, with the milking robot(s) consuming $0.5 \mathrm{~L} / \mathrm{L}$, with $37 \%$ of this water coming from a recycled source (e.g., water from the pre-cooling process). However, the water requirement for washing down the milking area in the current study was less than that for washing down CM parlors, as outlined by Murphy et al. (2014).
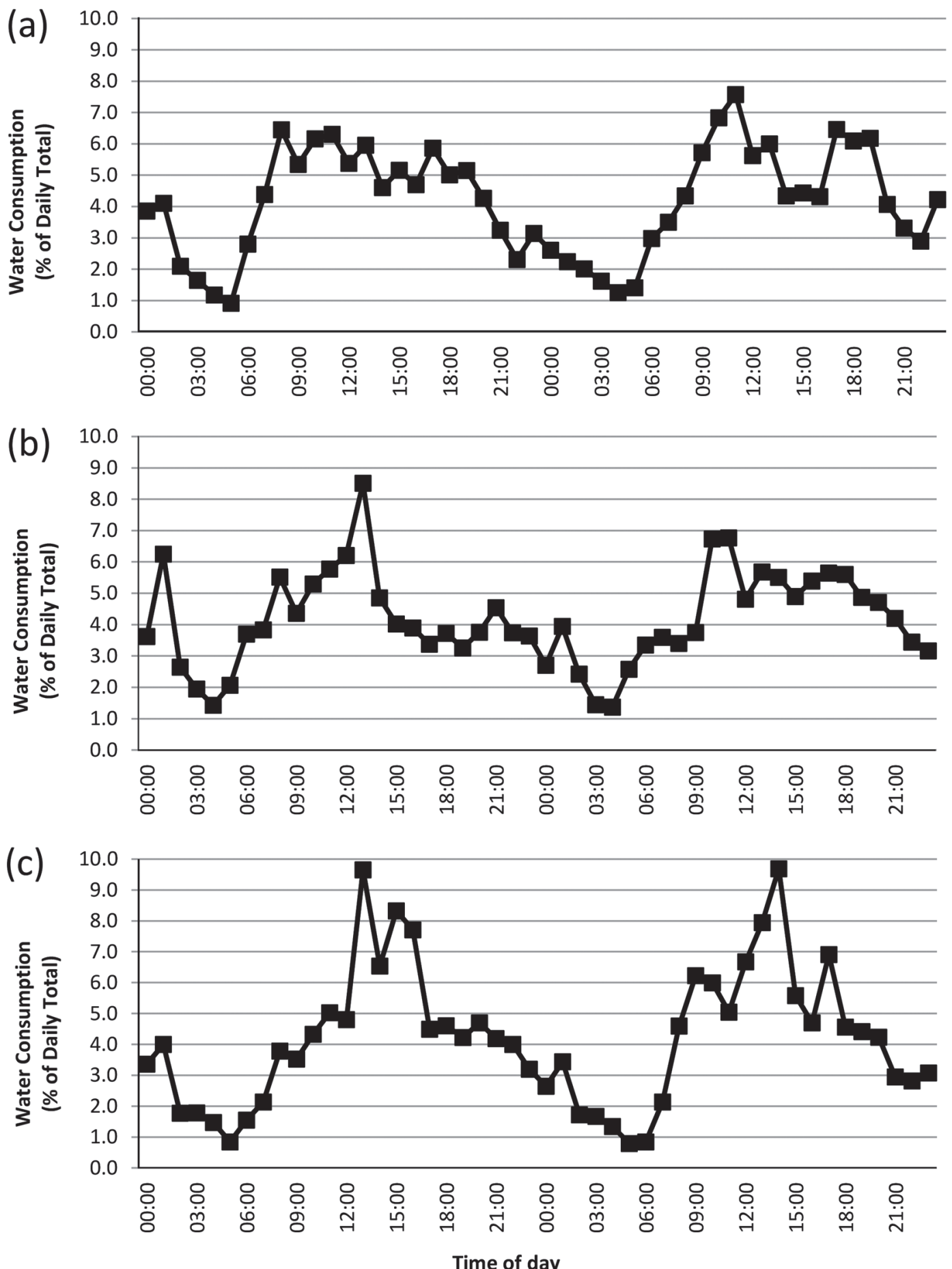

Figure 5. Average percentage of daily total direct water consumption on farm in (a) early lactation (March 24 to 25, 2015), (b) peak lactation (May 25 to 26, 2015), and (c) late lactation (September 15 to 16, 2015) for 7 pasture-based commercial automatic milking farms. 
This may be a consequence of the AM unit requiring a smaller housing area and cow collecting yard, resulting in a reduced area of solid concrete flooring requiring washing compared with CM parlors. Therefore, opportunity exists to find other suitable uses for this recycled tubular cooler water on AM farms.

The average AM unit in this study used 159,399 L of water per annum. This equates to $4.3 \mathrm{~L}$ per milking, similar to the average of $4.7 \mathrm{~L}$ outlined by Jensen (2009) for AM units of similar make and type to those examined here, although those authors operated in contrasting production systems. The average single-unit AM configuration used $24 \%$ more water on an annual basis than the average double-unit configuration, but consumed $12.5 \%$ less per milking event over the 12 -mo period measured. This is likely to be a consequence of the different stocking densities on the AM units, resulting in the dilution of water used within the AM unit across a greater number of milkings.

On-farm well water used by livestock and miscellaneous purposes was $32 \mathrm{~L} /$ cow per day, slightly less than the $35 \mathrm{~L} /$ cow per day outlined by Higham et al. (2017). However, as there was surplus water from the tubular cooler due to the small portion recycled for washing, $\mathrm{AM}$ farms were able to store this water and use for it for livestock drinking consumption or miscellaneous purposes. This led to a further 403,288 L of recycled water being consumed by livestock or miscellaneous process, replacing on-farm well water. Thus, total livestock and miscellaneous consumption was $42 \mathrm{~L} /$ cow per day, with $23 \%$ of this provided from a recycled source. Morris et al. (2010) and Jago et al. (2005) outlined that lactating dairy cows consumed 41 and $54 \mathrm{~L} /$ cow per day, respectively, at varying lactation stages, whereas Higham et al. (2017) found that, before accounting for any potential leaks in the drinking water network, average consumption across a 12-mo period may be as high as $60 \mathrm{~L} /$ cow per day.

Seasonal water use followed a similar pattern to the milk production curve of a spring calving system, with lowest demand for water in the winter months and highest demand in the summer months. This was expected, as spring-calving herds have the majority of cows milking in the summer months, resulting in a greater number of milkings in each day. With this comes greater water consumption in the form of additional between-milking cluster cleaning and tubular cooler consumption. Additionally, drinking water consumed by livestock is greatest in the summer months (Higham et al., 2017). However, the seasonal water trend deviated from the milk production curve in May, with this month recording above-average rainfall (Met Éireann, 2015), resulting in livestock drinking less.
Morris et al. (2010) demonstrated that a daily rainfall level of $26 \mathrm{~mm}$ can reduce livestock drinking water consumption by as much as $62 \%$. Again, when the trend of water consumption was analyzed per liter of milk a dilution effect (or lack thereof) could clearly be observed, with the months with the lowest milk production and water use recording the greatest consumption per liter of milk. Similar to electricity consumption, water consumption was at its lowest in the early morning period (0400-0600 $\mathrm{h}$ ) when AM unit utilization is traditionally at its lowest (John et al., 2016). As $>70 \%$ of water consumption occurs between 0900 and $2359 \mathrm{~h}$, it was not surprising that water pumping recorded the highest proportion of electricity usage during the more expensive day tariff period.

\section{Additional Considerations}

Achieving a large and consistent number of milkings throughout the year is not realistic in a seasonal calving system, as the majority of the herd reaches maximum milk production at the same time. Whereas the average number of milkings per AM unit per day was 105 across the year on the farms analyzed in the current study, the average number of milkings pre AM unit per day at peak milk production was 128 (range $=99-159)$ from an average of 58 cows (range $=45-82$ ). These figures were lower than the potential maximum number of milkings per AM unit per day of 180 from 77 cows for a seasonal calving system, as outlined by Lyons and Kerrisk (2017). As observed in the current study, increasing the number of milkings per AM unit had an effect on reducing the electricity consumption per liter of milk. Replicating the potential performance at peak milk production, as outlined by Lyons and Kerrisk (2017), would have a positive effect, but would require an efficient milking strategy.

Ferneborg and Svennersten-Sjaunja (2015) and Ferneborg et al. (2016) have described potential pulsation settings and cluster removal strategies, respectively, to increase the throughput of cows through the AM unit, thus increasing the number of milkings per day. Whereas electricity usage associated with milk cooling, vacuum, and milk pumps and compressed air would increase in accordance with increased milkings per AM unit, water heating costs would reduce, as hot washing of the AM unit is performed at a fixed frequency each day irrespective of the number of milkings. A similar scenario applies to water consumption, with a fixed quantity of water required per wash cycle. Therefore, an increased number of milkings would result in a dilution of the costs associated with (hot) washing of the AM unit. However, it should also be taken into consid- 
eration that increasing the milkings per AM unit may accelerate the maintenance and replacement of machine parts (Lyons and Kerrisk, 2017).

\section{CONCLUSIONS}

This study provides an understanding of the factors contributing to the daily and seasonal trends of electricity and water use on pasture-based AM farms. Milking and compressed air were the largest and most expensive consumers of electricity. Although farms with single-unit configurations consumed more electricity (total kWh per annum) than double-unit configurations, we found no difference in consumption per milking, indicating that increased consumption was caused by a greater ratio of cows per AM unit on single-unit farms. Trends indicate that although electricity consumption by the AM unit and air compressor increased with increased milkings, consumption per liter of milk produced was reduced. Water for livestock or miscellaneous purposes and for precooling milk were the largest consumers of on-farm direct water. Both seasonal and daily trends in consumption were similar for electricity and water consumption, with seasonal trends following the milk production curve of a seasonal production system. These findings have the potential to assist in developing future strategies that may improve the competiveness of the AM system.

\section{ACKNOWLEDGMENTS}

We acknowledge funding for this research from the European Union's Seventh Framework Program managed by REA-Research Executive Agency [http://ec .europa.eu/research/rea (FP7/2007-2013), under grant agreement no. SME-2012-2-314879]. The authors also acknowledge the Teagasc Walsh Fellowship program (Ref 2012015), which directly funded the first author.

\section{REFERENCES}

Artmann, R., and E. Bohlsen. 2000. Results from the implementation of automatic milking system (AMS)-multi-box facilities. Pages 221-231 in Robotic Milking: Proc. Int. Symp. H. Hogeveen and A. Meijering, ed. Wageningen Academic Publishers, Wageningen, the Netherlands.

Bijl, R., S. R. Kooistra, and H. Hogeveen. 2007. The profitability of automatic milking on Dutch dairy farms. J. Dairy Sci. 90:239-248.

Calcante, A., F. M. Tangorra, and R. Oberti. 2016. Analysis of electric energy consumption of automatic milking systems in different configurations and operative conditions. J. Dairy Sci. 99:4043-4047.

CSO. 2017. Milk Statistics, December 2016. Central Statistics Office, Dublin Ireland. Accessed Jun. 2, 2017. http://www.cso.ie/en/ releasesandpublications/er/ms/milkstatisticsdecember2016/.

DAFM. 2010. Food harvest 2020-A vision for Irish agri-food and fisheries. Department of Agriculture Food and the Marine. Dub- lin, Ireland. Accessed Jun. 1, 2016. https://www.agriculture.gov .ie/media/migration/foodindustrydevelopmenttrademarkets/ a gri - foodand theeconomy / foodharvest 2020 / 2020FoodHarvestEng240810.pdf.

DAFM. 2015. Food wise 2025-A 10 year vision for the Irish agri-food industry. Department of Agriculture Food and the Marine. Dublin, Ireland. Accessed Jun. 1, 2016. https://www.agriculture.gov .ie/media/migration/foodindustrydevelopmenttrademarkets/agri -foodandtheeconomy/foodwise2025/report/FoodWise2025.pdf.

Dillon, P., L. Hanrahan, F. Thorne, P. Kelly, L. Shalloo, and B. Moran. 2016. Irish dairying: Well positioned for the upturn. Pages 8-27 in Technologies for Success: Teagasc National Dairy Conference. Teagasc Moorepark, Cork, Ireland. Accessed Jan. 25, 2017. https:// www.teagasc.ie/media/website/publications/2016/National-Dairy -conference-Proceedings.pdf.

Ferneborg, S., L. Stadtmüller, J. Pickova, L. Wiking, and K. Svennersten-Sjaunja. 2016. Effects of automatic cluster removal and feeding during milking on milking efficiency, milk yield and milk fat quality. J. Dairy Res. 83:180-187.

Ferneborg, S., and K. Svennersten-Sjaunja. 2015. The effect of pulsation ratio on teat condition, milk somatic cell count and productivity in dairy cows in automatic milking. J. Dairy Res. 82:453-459.

Higham, C. D., D. Horne, R. Singh, B. Kuhn-Sherlock, and M. R. Scarsbrook. 2017. Water use on nonirrigated pasture-based dairy farms: Combining detailed monitoring and modeling to set benchmarks. J. Dairy Sci. 100:828-840.

Irish Water. 2016. CER Consumption Reporting. Irish Water, Dublin, Ireland. Accessed Jun. 1, 2016. https://www.water.ie/for -home/metering-explained/consumption-reports/Q2-2015-CER -Consumption-Report.pdf.

Jago, J. G., K. L. Davis, M. Newman, and M. W. Woolford. 2006. An economic evaluation of automatic milking systems for New Zealand dairy farms. Proc. N.Z. Soc. Anim. Prod. 66:263-269.

Jago, J. G., J. R. Roche, E. S. Kolver, and M. W. Woolford. 2005. The drinking behaviour of dairy cows in late lactation. Proc. N.Z. Soc. Anim. Prod. 65:209-214.

Jensen, M. L. 2009. Power and water consumption - with AMS. 61st ed, Farm Test Cattle. Dansk Landbrugsradgivning, Dansk Kvaeg, Aarhus, Denmark. Accessed Jun. 1, 2016. http://www .milkproduction.com/Documents/Farmtest61-AMS-UK-web.pdf.

John, A. J., C. Clark, M. Freeman, K. Kerrisk, S. Garcia, and I. Halachmi. 2016. Review: Milking robot utilization, a successful precision livestock farming evolution. Animal 10:1484-1492.

Lips, M., and P. Rieder. 2005. Abolition of raw milk quota in the European Union: A CGE analysis at the member country level. J. Agric. Econ. 56:1-17.

Lyons, N. A., and K. L. Kerrisk. 2017. Current and potential system performance on commercial automatic milking farms. Anim. Prod. Sci. 57:1550-1556.

Lyons, N. A., K. L. Kerrisk, and S. C. Garcia. 2013. Comparison of 2 systems of pasture allocation on milking intervals and total daily milk yield of dairy cows in a pasture-based automatic milking system. J. Dairy Sci. 96:4494-4504.

Mathijs, E. 2004. Socio-economic aspects of automatic milking. Pages 46-55 in Proceedings of Automatic Milking: A Better Understanding. A. Meijering, H. Hogeveen, and C.J.A.M. de Koning, ed. Wageningen Academic Publishers, Wageningen, the Netherlands.

Met Éireann. 2015. Monthly Weather Bulletin - May 2015. Met Éireann, Dublin, Ireland. Accessed Jun. 1, 2016. http://www.met.ie/ climate/monthly-weather-reports.asp.

Morris, C. A., S. M. Hickey, E. R. Thom, and C. D. Waugh. 2010. Daily water intake by individual dairy cows on a pasture diet during mid lactation. Proc. N.Z. Soc. Anim. Prod. 70:257-260.

Murphy, E., I. J. M. de Boer, C. E. van Middelaar, N. M. Holden, L. Shalloo, T. P. Curran, and J. Upton. 2017. Water footprinting of dairy farming in Ireland. J. Clean. Prod. 140:547-555.

Murphy, E., J. Upton, N. M. Holden, and T. P. Curran. 2014. Direct water use on Irish dairy farms. Pages 146-148 in Biosystems Engineering Research Review 19. E. J. Cummins and T. P. Curran, ed. University College Dublin, Dublin, Ireland. 
O’Donnell, S., L. Shalloo, A. M. Butler, and B. Horan. 2008. A survey analysis of opportunities and limitations of Irish dairy farmers. J. Farm Manag. 13:419-434.

Ridoutt, B. G., S. R. O. Williams, S. Baud, S. Fraval, and N. Marks. 2010. Short communication: The water footprint of dairy products: Case study involving skim milk powder. J. Dairy Sci. 93:5114-5117.

Rotz, C. A., C. U. Coiner, and K. J. Soder. 2003. Automatic milking systems, farm size, and milk production. J. Dairy Sci. 86:41674177.

SEAI. 2016. Domestic fuels comparison of energy costs. Sustainable Energy Authority of Ireland (SEAI), Dublin, Ireland. Accessed Jun. 1, 2016. https://www.seai.ie/resources/publications/ Domestic-Fuel-Cost-Comparisons.pdf.

Shortall, J., L. Shalloo, C. Foley, R. D. Sleator, and B. O'Brien. 2016. Investment appraisal of automatic milking and conventional milking technologies in a pasture-based dairy system. J. Dairy Sci. 99:7700-7713.

Steeneveld, W., L. W. Tauer, H. Hogeveen, and A. G. J. M. Oude Lansink. 2012. Comparing technical efficiency of farms with an automatic milking system and a conventional milking system. J. Dairy Sci. 95:7391-7398.
Teagasc. 2017. The people in dairy project: A report on the future people requirements of Irish dairy farming to support sustainable and profitable dairy expansion, Teagasc Moorepark, Fermoy, Co. Cork. Accessed Jun. 2, 2017. https://www.teagasc.ie/media/website/ publications /2017/The-People-in-Dairy-Project.pdf.

Upton, J., J. Humphreys, P. W. G. Groot Koerkamp, P. French, P. Dillon, and I. J. M. De Boer. 2013. Energy demand on dairy farms in Ireland. J. Dairy Sci. 96:6489-6498.

Upton, J., M. Murphy, I. J. M. De Boer, P. W. G. Groot Koerkamp, P. B. M. Berentsen, and L. Shalloo. 2015a. Investment appraisal of technology innovations on dairy farm electricity consumption. J. Dairy Sci. 98:898-909.

Upton, J., M. Murphy, L. Shalloo, P. Koerkamp, and I. J. M. De Boer. 2015b. Assessing the impact of changes in the electricity price structure on dairy farm energy costs. Appl. Energy 137:1-8.

Upton, J., and B. O'Brien. 2013. Analysis of energy consumption in robotic milking. Pages 465-470 in Proceedings of Precision Livestock Farming '13. D. Berckmans and J. Vandermeulen, ed. Katholieke Universiteit Leuven, Leuven, Belgium. 